\title{
Methanation of carbon dioxide by hydrogen reduction - a thermodynamic analysis
}

\author{
Robert Kaczmarczyk ${ }^{1, *}$, Agata Mlonka-Mędrala ${ }^{1}$, and Sebastian Gurgul ${ }^{2}$ \\ ${ }^{1}$ AGH University of Science and Technology, Faculty of Energy and Fuel, 30-059 Krakow \\ Mickiewicza 30, Poland \\ ${ }^{2}$ MTU Aero Engines Polska Sp. z o.o., 36-002 Jasionka Tajecina 108, Poland
}

\begin{abstract}
The paper presents a thermodynamic analysis of the methanation of carbon dioxide by hydrogen reduction. Equilibrium gas phase composition was determined by means of parametric equations. Calculations were performed for the temperature range $\mathrm{T}=500-700 \mathrm{~K}$ and the initial composition $x_{\mathrm{CO}_{2}}^{0} \in(0-1)$.. A crucial parameter for catalytic processes, carbon precipitation range $[\mathrm{C}]=f\left(T, x_{\mathrm{CO}_{2}}^{0}\right)$ was presented as a function of temperature and an initial gas phase $\mathrm{CO}_{2}-\mathrm{H}_{2}$ composition. The $\mathrm{CO}_{2}$ conversion efficiency and the methane yield in the process was determined. Obtained results may be used for experimental research prediction and in industrial pragmatic.
\end{abstract}

\section{Introduction}

A catalytic reduction of carbon oxides by hydrogen is commonly used in syngas treatment. Methane is the main product of the process. In a so-called methanation process, the overall content of carbon oxides in the syngas is reduced from $0.2-0.5 \% \mathrm{v}$ to less than 2 ppmv [1]. The syngas treatment is crucial in the synthesis of ammonia. [2] Carbon monoxide appears to be destructive for the catalysts in the process. The methanation process can be used to reduce the $\mathrm{CO}$ content in the synthesis gas. The most commonly used catalyst in the methanation technologies is a nickel oxide on alumina support [3]. However, ruthenium catalysts possess higher activity than nickel oxide. The most common catalyst supports are: $\mathrm{Al}_{2} \mathrm{O}_{3}, \mathrm{MgO}, \mathrm{MgAl}_{2} \mathrm{O}_{4}, \mathrm{SiO}_{2}, \mathrm{FeO}$ [4,5] and activated carbon [6]. In the power industry, methanation process may be used for waste $\mathrm{CO}_{2}$ utilization from fossil-fuel combusting units $(\mathrm{CCU})$. In the coal-gasification process, synthesis gas and hydrocarbons from further conversion (eg. in Fischer-Tropsch synthesis) are produced [7-19]. However, these technologies generates high $\mathrm{CO}_{2}$ emissions and affect the final product cost. [20, 21]. The innovative technologies for hydrocarbons generation from a mixture of carbon dioxide and hydrogen tie a valuable product generation with a waste product utilization. Thermodynamics and kinetics of the hydrocarbon synthesis form carbon dioxide and hydrogen mixture ware widely described in $[22,23]$. However, only mixtures of the stoichiometric composition under standard pressure were analyzed. The synthesis of hydrocarbons was considered as a kinetically controlled polymerization process of the $-\left[\mathrm{CH}_{2}\right]-$ groups on the catalyst surface.

*Corresponding author: robertk@agh.edu.pl 
Under favorable conditions the final composition of the synthesis product will be correlated with a so-called ASF distribution (Anderson-Schulz-Flory) with the growth probability of hydrocarbons $(\alpha)$ [24,25]. The ASF equation is used for description of the hydrocarbon synthesis reaction form $\mathrm{CO}-\mathrm{H}_{2}$ and $\mathrm{CO}_{2}-\mathrm{H}_{2}$ mixtures. In [26-28] the detailed mechanisms of the carbon dioxide hydrogenation are presented.

\section{A thermodynamic analysis of carbon dioxide methanation process by means of parametric equations method}

A characteristic of carbon dioxide methanation process was accomplished based on thermodynamic fundamental principles, thermodynamic properties of pure substances taking part in the reaction and properties of solutions formed in the gas phase. For a given chemical reaction, the Gibbs free energy change $\Delta G_{T}^{0}$ was determined:

$$
\Delta G_{T}^{0}=\sum_{i=1}^{m_{1}} k_{B_{i}} \cdot \mu_{B_{i}}^{0}-\sum_{i=1}^{m_{2}} k_{A_{i}} \cdot \mu_{A_{i}}^{0}
$$

Where: $A_{i}, i=1, \ldots m_{1}$ and $B_{i}, i=1, \ldots m_{2}$ are reactants and products respectively, $k_{A i}$ and $k_{B i}$ are stoichiometric coefficients, $\mu_{A_{i}}^{0}$ and $\mu_{B_{i}}^{0}$ represents standard chemical potential of pure substances. The relation between Gibbs free energy change and thermodynamic equilibrium constant $\mathrm{K}$ is presented below:

$$
\Delta G_{T}^{0}=-R T \ln K
$$

where: $\mathrm{K}$ represents the tendency of the process and is determined by reagents activities $\mathrm{a}_{\mathrm{i}}$.

$$
K=\frac{\prod_{i=1}^{s} a_{B_{i}}^{k_{B_{i}}}}{\prod_{i=1}^{s} a_{A_{i}}^{k_{A_{i}}}}
$$

The activity of pure components in solid or liquid phase is equal to unity. The activities of chemical species in the gas phase can be determined by the components partial pressures $\mathrm{P}_{\mathrm{i}}=\mathrm{x}_{\mathrm{i}} \mathrm{P}_{\text {tot }}\left(\mathrm{P}_{\text {tot }}-\right.$ the total system pressure $)$. In isothermal-isobaric conditions, the composition of the gas phase changes linearly and a conversion from initial to final (equilibrium) state can be described by a vector parallel to the linear function [29-32]:

$$
x_{i}=x_{i}^{0}+\tau \frac{k_{i}-x_{i}^{0} \sum_{i=1}^{S} k_{i}}{\sqrt{\sum_{i=1}^{S}\left(k_{i}-x_{i}^{0} \sum_{i=1}^{S} k_{i}\right)^{2}}}
$$

where $x_{i}, x_{i}^{0}$ - equilibrium and initial molar fraction of ,i” component, $\tau \in \mathrm{R}$ - straight line parameter, $\mathrm{k}_{\mathrm{i}}-$, il” reagent stoichiometric coefficient. Positive stoichiometric coefficients $\left(\mathrm{k}_{\mathrm{i}}\right)$ are defined for products and negative for reactants. The direction cosines are time independent and they are functions of initial composition and stoichiometric coefficients only. In the reaction $\left(\sum_{i=1}^{s} k_{i} \neq 0\right)$ the phase composition change proceed linearly and the lines are intersecting at a so-called "characteristic point" $\left(\overline{x_{l}}\right)$. In case of the reaction $\left(\sum_{i=1}^{s} k_{i}=0\right)$, the direction cosine depends on stoichiometric coefficients only. Initial composition does not affect the direction cosine and a change of reagents concentration proceed linearly and the lines are parallel to each other. The presented computational process analysis was carried out based on thermodynamic data [33] and a numerical computing environment - MATLAB. 
The catalytic carbon dioxide methanation process over a nikel-based catalyst may be described as follows:

$$
\underset{\mathrm{Ni}}{\stackrel{\mathrm{T}}{\rightarrow}}\left(\mathrm{CO}_{2}-\mathrm{H}_{4}, \mathrm{H}_{2} \mathrm{O}, \mathrm{H}_{2}, \mathrm{CO}_{2}, \mathrm{CO}\right)
$$

The main products the methanation process are methane, water vapor and other contaminations like: unreacted carbon dioxide, hydrogen and carbon monoxide. The model reactions of the methanation process are presented in Tab. 1.

Table 1. Model reactions $(\mathrm{j}=3)$ for methanation $\mathrm{CO}_{2}-\mathrm{H}_{2}$ process.

\begin{tabular}{|c|c|c|}
\hline $\mathrm{j}$ & Reaction & $\sum_{i=1}^{5} k_{i}$ \\
\hline 1 & $\mathrm{CO}_{2(g)}+4 \mathrm{H}_{2(g)} \leftrightarrow \mathrm{CH}_{4(g)}+2 \mathrm{H}_{2} \mathrm{O}_{(g)}$ & -2 \\
\hline 2 & $\mathrm{CH}_{4(g)}+\mathrm{H}_{2} \mathrm{O}_{(g)} \leftrightarrow \mathrm{CO}_{(g)}+3 \mathrm{H}_{2(g)}$ & 2 \\
\hline 3 & $\mathrm{CO}_{(g)}+\mathrm{H}_{2} \mathrm{O}_{(g)} \leftrightarrow \mathrm{CO}_{2(g)}+\mathrm{H}_{2(g)}$ & 0 \\
\hline
\end{tabular}

\begin{tabular}{|c|c|c|c|}
\hline \multirow[t]{2}{*}{$\mathrm{i}$} & $\left\{\begin{array}{r}d l a \sum_{i=1}^{5} k_{i} \neq 0= \\
\text { dla } \sum_{i=1}^{5}\end{array}\right.$ & $\begin{array}{l}\left(\bar{x}_{i}-x_{i}^{0}\right) \tau, \quad \text { gdzie } \bar{x}_{i} \\
\Rightarrow x_{i}^{0}+\tau \frac{k_{i}}{\sqrt{\sum_{i=1}^{5}\left(k_{i}\right)^{2}}}\end{array}$ & $\frac{k_{i}}{=k_{i} k_{i}}$ \\
\hline & $\mathrm{j}=1$ & $\mathrm{j}=2$ & $j=3$ \\
\hline $\mathrm{CH}_{4}$ & $x_{C_{4}}^{o}+\left(-0.5-x_{C H_{4}}^{0}\right) \tau$ & $x_{\mathrm{CH}_{4}}^{o}+\left(-0.5-x_{\mathrm{CH}_{4}}^{0}\right) \tau$ & $x_{C H_{4}}^{o}$ \\
\hline $\mathrm{H}_{2} \mathrm{O}$ & $x_{\mathrm{H}_{2} \mathrm{O}}^{\mathrm{O}}+\left(-1-x_{\mathrm{H}_{2} \mathrm{O}}^{0}\right) \tau$ & $x_{\mathrm{H}_{2} \mathrm{O}}^{o}+\left(-0.5-x_{\mathrm{H}_{2} \mathrm{O}}^{0}\right) \tau$ & $x_{\mathrm{H}_{2} \mathrm{O}}^{o}-0.5 \tau$ \\
\hline$H_{2}$ & $x_{H_{2}}^{o}+\left(2-x_{H_{2}}^{0}\right) \tau$ & $x_{H_{2}}^{o}+\left(1.5-x_{H_{2}}^{0}\right) \tau$ & $x_{\mathrm{H}_{2}}^{o}+0.5 \tau$ \\
\hline $\mathrm{CO}_{2}$ & $x_{\mathrm{CO}_{2}}^{o}+\left(0.5-x_{\mathrm{CO}_{2}}^{0}\right) \tau$ & $x_{\mathrm{CO}_{2}}^{o}-x_{\mathrm{CO}_{2}}^{0} \tau$ & $x_{\mathrm{CO}_{2}}^{o}+0.5 \tau$ \\
\hline $\mathrm{CO}$ & $x_{C O}^{o}-x_{C O}^{0} \tau$ & $x_{C O}^{o}+\left(0.5-x_{C O}^{0}\right) \tau$ & $x_{C O}^{o}-0.5 \tau$ \\
\hline
\end{tabular}

Table 2. The parametric equations for equilibrium concentrations calculations of the methanation process

The parametric equations for all model reactions and compounds $\left(\mathrm{CH}_{4}, \mathrm{H}_{2} \mathrm{O}, \mathrm{H}_{2}, \mathrm{CO}_{2}, \mathrm{CO}\right)$ are presented in Tab. 2. For a given initial composition $x_{i}^{0}\left(\mathrm{i}=\mathrm{CO}_{2}, \mathrm{H}_{2}\right)$ equilibrium concentration $x_{i}$ for the first model reaction was determined. The $\tau$-parameter was calculated by substitution of the corresponding parametric equations to the equilibrium constant $\mathrm{K}$ formula. For the model reaction $(j=1)$ equilibrium constant is defined as:

$$
K_{1}=\frac{P_{\mathrm{CH}_{4}} P_{\mathrm{H}_{2} \mathrm{O}}^{2}}{P_{\mathrm{CO}_{2}} P_{\mathrm{H}_{2}}^{4}}=\frac{x_{\mathrm{CH}_{4}} x_{\mathrm{H}_{2} \mathrm{O}}^{2}}{x_{\mathrm{CO}_{2}} x_{\mathrm{H}_{2}}^{4}} P^{-2} ; \text { where } P=1[\mathrm{~atm}]
$$




$$
K_{1}=\frac{\left[x_{C H_{4}}^{o}+\left(-0.5-x_{C H_{4}}^{0}\right) \tau\right] \cdot\left[x_{\mathrm{H}_{2} \mathrm{O}}^{o}+\left(-1-x_{\mathrm{H}_{2} \mathrm{O}}^{0}\right) \tau\right]^{2}}{\left[x_{C O_{2}}^{o}+\left(0.5-x_{\mathrm{CO}_{2}}^{0}\right) \tau\right] \cdot\left[x_{\mathrm{H}_{2}}^{o}+\left(2-x_{\mathrm{H}_{2}}^{0}\right) \tau\right]^{4}}
$$

For a given initial gas composition (e.g.: $x_{\mathrm{CO}_{2}}^{o}=x_{\mathrm{H}_{2}}^{o}=0.5, x_{\mathrm{CH}_{4}}^{o}=x_{\mathrm{H}_{2} \mathrm{O}}^{o}=0$,) a function is written as follows:

$$
5.0625 K_{1} \tau^{4}+\left(6.75 K_{1}+1\right) \tau^{3}+3.375 K_{1} \tau^{2}+0.75 K_{1} \tau+0.625 K_{1}=0
$$

The function has 4 roots $\left(\tau_{1}, \tau_{2}, \tau_{3}, \tau_{4}\right)$, equilibrium composition is calculated for each root by means of parametric equations for all components of the gas phase. A given $\tau$-parameter has a physical meaning when: $0 \leq x_{i} \leq 1$ and $\sum_{i=1}^{5} x_{i}=1$. The equilibrium composition of the first reaction determines the initial composition of the second one and so on. Calculations were carried out in a loop, till the final composition fulfills all equilibrium constants for all the model reactions. In the methanation process, carbon precipitate is formed according to reactions in Tab. 3. The formation of pure carbon precipitate is limited by gas phase components concentration $\operatorname{ratios}(\alpha, \beta, \gamma) . K_{\alpha}, K_{\beta}, K_{\gamma}$ are the reactions equilibrium constants. The activity of the formed carbon precipitate is equal to unity $\left(\mathrm{a}_{[\mathrm{C}]}=1\right)$.

Table 3. An interpretation of the carbon precipitation process in the gas phase

\begin{tabular}{|c|c|c|c|c|}
\hline rection & $\alpha$ & $\beta$ & $\gamma$ & $a_{[C]}=1$ \\
\hline $\mathrm{CH}_{4} \leftrightarrow[\mathrm{C}]+2 \mathrm{H}_{2}$ & $x_{\mathrm{H}_{2}}^{2} / x_{\mathrm{CH}_{4}}$ & & & \multirow{3}{*}[C]{$=\left\{\begin{array}{l}M \leq K_{\alpha} \\
B \geq K_{\beta} \\
R \leq K_{\gamma}\end{array}\right.$} \\
\hline$[\mathrm{C}]+\mathrm{CO}_{2} \leftrightarrow 2 \mathrm{CO}$ & & $x_{\mathrm{CO}}^{2} / x_{\mathrm{CO}_{2}}$ & & \\
\hline $\mathrm{CO}+\mathrm{H}_{2} \leftrightarrow[\mathrm{C}]+\mathrm{H}_{2} \mathrm{O}$ & & & $x_{\mathrm{H}_{2} \mathrm{O}} / x_{\mathrm{CO}} x_{\mathrm{H}_{2}}$ & \\
\hline
\end{tabular}

$$
\left(\mathrm{CH}_{4}, \mathrm{H}_{2} \mathrm{O}, \mathrm{H}_{2}, \mathrm{CO}_{2}, \mathrm{CO}\right) \text {. }
$$

The analysis of methanation process in the thermodynamic equilibrium conditions was carried out for a temperature range $500-700 \mathrm{~K}$ and for initial concentrations $x_{\mathrm{CO}_{2}}^{0}=0 \div 1$. For the obtained results, the carbon precipitation range as a function of the temperature and the initial gas phase composition was presented in Fig. 1.

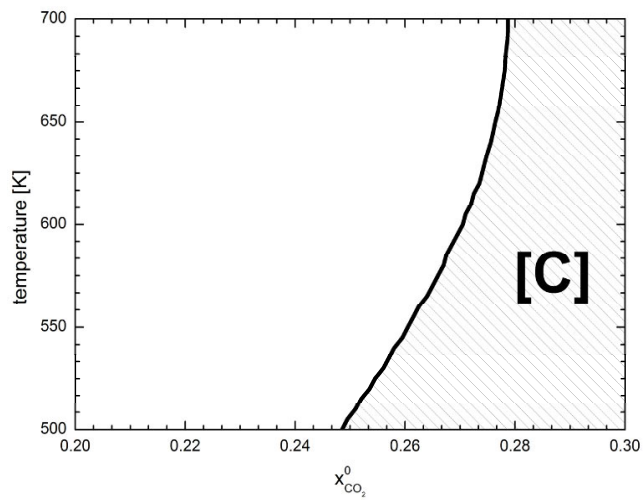

Fig. 1. The carbon precipitation range $[C]=f\left(T, x_{\mathrm{CO}_{2}}^{0}\right)$ as a function of temperature and an initial gas phase $\mathrm{CO}_{2} / \mathrm{H}_{2}$ composition. 
In the analyzed temperature range, carbon precipitation starts in the initial conditions: $x_{\mathrm{CO}_{2}}^{0}>$ 0.248 at $500 \mathrm{~K}$ and $x_{\mathrm{CO}_{2}}^{0}>0.279$ at $700 \mathrm{~K}$. Further analysis was limited to carbon precipitation free range. The gas phase equilibrium concentrations in the analyzed process for initial compositions $x_{\mathrm{CO}_{2}}^{0}=0 \div 0.3$ are shown in Fig. 2. At $\mathrm{T}=500 \mathrm{~K}$, when the $\mathrm{CO}_{2}$ initial concentration increases, the equilibrium concentrations of $\mathrm{CH}_{4}$ and $\mathrm{H}_{2} \mathrm{O}$ increase as well, until the maximum concentration is achieved $\left(\mathrm{CH}_{4}=32.38 \% ; \mathrm{H}_{2} \mathrm{O}=64.77 \%\right)$. It represents a so-called stoichiometric methanation process $\left(x_{\mathrm{CO}_{2}}^{0}=0.2 ; x_{\mathrm{H}_{2}}^{0}=0.8\right)$. Hydrogen equilibrium concentration in under-stoichiometric range of concentrations $\left(x_{\mathrm{CO}_{2}}^{0}<0.2\right)$ decreases from $80 \%$ to $2.3 \% \quad\left(x_{\mathrm{CO}_{2}}^{0}=0.2\right)$. In these conditions, there is no $\mathrm{CO}$ and $\mathrm{CO}_{2}$ in the equilibrium gas phase. In the over-stoichiometric range of concentrations $\left(x_{\mathrm{CO}_{2}}^{0}>0.2\right)$ concentration of $\mathrm{CH}_{4}$ and $\mathrm{H}_{2} \mathrm{O}$ is decreased, concentration of $\mathrm{H}_{2}$ is stable and concentration of $\mathrm{CO}_{2}$ is increased. The $\mathrm{CO}$ content in the gas phase changes around 1-11 ppm $\left(x_{\mathrm{CO}_{2}}^{0}=0.2-0.24\right)$. The maximal value of the equilibrium concentration functions $x_{\left(\mathrm{CH}_{4}, \mathrm{H}_{2} \mathrm{O}\right)}=f\left(x_{\mathrm{CO}_{2}}^{0}\right)$ decreases with the temperature increase. At $\mathrm{T}=700 \mathrm{~K}$ the maximal concentrations of methane and water vapor are lower than the stoichiometric concentrations at $500 \mathrm{~K}$ and are equal to $\mathrm{CH}_{4}=23.81 \% ; \mathrm{H}_{2} \mathrm{O}=47.89 \%$. The increase of equilibrium concentrations of hydrogen, carbon dioxide and carbon monoxide $\mathrm{H}_{2}=22.59 \% ; \mathrm{CO}_{2}=$ $5.45 \%, C O=0.27 \%$ ) is observed in the initial conditions $x_{\mathrm{CO}_{2}}^{0} \geq 0.2$. Therefore, the methanation process proceed more effectively at lower temperatures. At $500 \mathrm{~K}$ an increase of the $\mathrm{CO}_{2}$ conversation efficiency $\left(\eta_{\mathrm{CO}_{2}}\right)$ and methane yield $\left(y_{\mathrm{CH}_{4}}\right)$ might be observed (Fig. 3).

$$
\begin{gathered}
\eta_{\mathrm{CO}_{2}}=\frac{n_{\mathrm{CO}_{2}}^{0}-n_{\mathrm{CO}_{2}}}{n_{\mathrm{CO}_{2}}^{0}} \\
y_{\mathrm{CH}_{4}}=\eta_{\mathrm{CO}_{2}} \frac{n_{\mathrm{CH}_{4}}}{n_{\mathrm{CH}_{4}+n_{\mathrm{CO}}}}
\end{gathered}
$$

where: $n^{0}, n-$ methanation process products and reactants number of moles

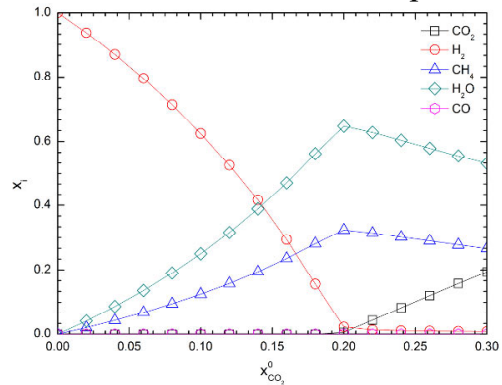

a.) $T=500 \mathrm{~K}$

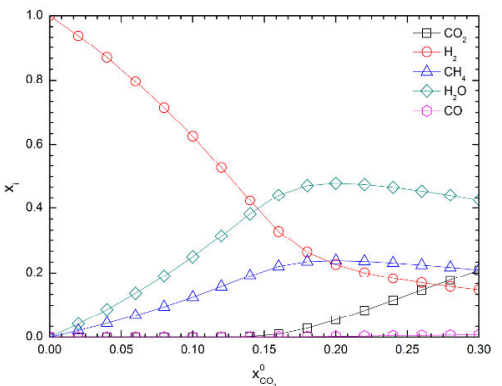

b.) $T=700 \mathrm{~K}$

Fig. 2. Equilibrium concentrations $x_{i}=f\left(x_{\mathrm{CO}_{2}}^{0}\right)$ of the gas phase $\left(\mathrm{i}=\mathrm{CH}_{4}, \mathrm{H}_{2} \mathrm{O}, \mathrm{H}_{2}, \mathrm{CO}_{2}, \mathrm{CO}\right)$ for the initial concentrations $x_{\mathrm{CO}_{2}}^{0}=0 \div 0.3$ 


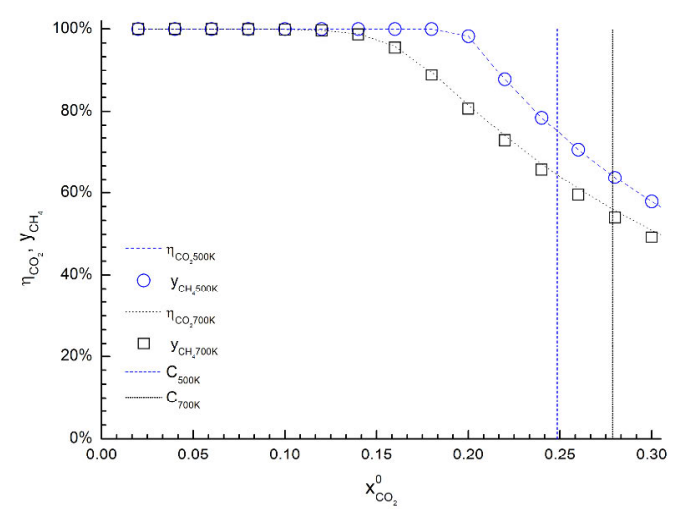

Fig. 3. $\mathrm{CO}_{2}$ conversion efficiency, methane yield and carbon precipitation range for methanation $\mathrm{CO}_{2} / \mathrm{H}_{2}$ process within the temperature range $\mathrm{T}=500-700 \mathrm{~K}, x_{\mathrm{CO}_{2}}^{0}=0 \div 3$.

The best results in methanation process of carbon dioxide by hydrogen are observed for a socalled stoichiometric initial gas phase composition $\left(x_{\mathrm{CO}_{2}}^{0}=0.2 ; x_{\mathrm{H}_{2}}^{0}=0.8\right)$. The stoichiometric composition is beyond the carbon precipitation range. Furthermore, the maximal methane concentration, a minimal $\mathrm{CO}, \mathrm{CO}_{2}$ and $\mathrm{H}_{2}$ concentration and $98 \%$ of $\mathrm{CO}_{2}$ conversion efficiency is obtained. The temperature increase of stoichiometric methanation $\mathrm{CO}_{2} / \mathrm{H}_{2}$ process decreases the methane concentration, methane yield and conversion efficiency of the process. However an increase of $\mathrm{CO}, \mathrm{CO}_{2}$ and $\mathrm{H}_{2}$ concentration in the process gases is observed. The characteristics of the stoichiometric methanation process is presented in Fig. 4.

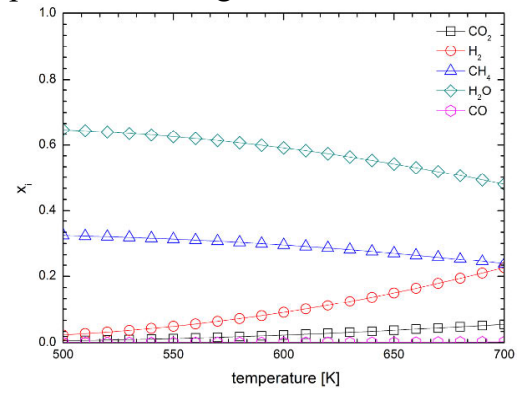

a.) $x_{i}=f(T),\left(i=\mathrm{CH}_{4}, \mathrm{H}_{2} \mathrm{O}, \mathrm{H}_{2}, \mathrm{CO}_{2}, \mathrm{CO}\right)$

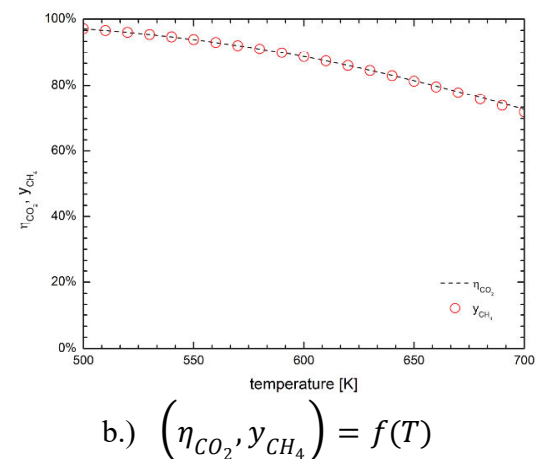

Fig. 4. The stoichiometric $\left(x_{\mathrm{CO}_{2}}^{0}=0.2 ; x_{\mathrm{H}_{2}}^{0}=0.8\right)$ methanation $\mathrm{CO}_{2} / \mathrm{H}_{2}$ process characteristic in a temperature function.

\section{Conclusions}

The maximal methane concentration in the reaction products is observed for the initial concentrations $\left(x_{\mathrm{CO}_{2}}^{0}=0.2 ; x_{\mathrm{H}_{2}}^{0}=0.8\right)$ coming from the stoichiometry of the reaction $(\mathrm{j}=1)$. Above the initial stoichiometric concentration, a decrease of an equilibrium concentration of methane, methane yield and $\mathrm{CO}_{2}$ conversion efficiency is observed. The temperature decreases the efficiency of methanation process. The increase of temperature and initial concentration $x_{\mathrm{CO}_{2}}^{0}$ promotes $\mathrm{CO}$ formation in the process gases. According to thermodynamics, in the analyzed temperature range, the carbon precipitation appears to be a problem for the initial concentration $x_{\mathrm{CO}_{2}}^{0}>0.248$ at $500 \mathrm{~K}$ and $x_{\mathrm{CO}_{2}}^{0}>0.279$ at $700 \mathrm{~K}$. 
The presented thermodynamic analysis in equilibrium conditions shows the direction and the limit of the gas phase composition, the real technological process will tend to.

The present work was supported by the Polish Ministry of Science (Grant AGH No. 11.11.210.312)

\section{References}

1. A. Gołębiowski, K. Stołecki, Przem. Chem. 80/11 (2001)

2. W. Bobrownicki, S. Pawlikowski, Technologia Związów Azotowych (WNT, Warszawa, 1974)

3. A.L. Kohl, F.C. Riesenfeld, Oczyszczanie gazu (WNT, Warszawa, 1965)

4. Z. Kowalczyk, K. Stołecki, W. Raróg-Pilecka, E. Miśkiewicz, E. Wilczkowska, Z. Karpiński, Appl. Catal., A, 342, 35-39 (2008)

5. W.K. Jóźwiak, T.P. Maniecki, Przem. Chem., 82/8-9 (2003)

6. Z. Kowalczyk, K. Stołecki, W. Raróg-Pilecka, E. Miśkiewicz, E. Wilczkowska, Z. Karpiński, Pol. J. Chem., 82, 607-612 (2008)

7. C.S. Song, W. Pan, Catal. Today, 98, 463-484 (2004)

8. B.H. Davis, Catal. Today, 141, 25-33 (2009)

9. B.H. Davis, Fuel Process. Technol., 71, 157-166 (2001)

10. B.H. Davis, M.L. Ocelli, Fischer-Tropsch Synthesis, Catalysts and Catalysis (Studies in Surface Science and Catalysis, Vol. 163, The Netherlands, 2006)

11. B.H. Davis, Top. Catal., 32, 143-162 (2005)

12. K. Dreszer, L. Więcła-Solny, Energ. Policy, 10, 189-201 (2007)

13. J. Hong, P.A. Chernavskii, A.Y. Khodakov, W. Chu, Catal. Today, 140, 136-141 (2009)

14. A.Y. Krylova, E.A. Kozyukov, Solid Fuel Chem., 41, 335- 341 (2007)

15. W. Liu, J. Hu, Y. Wang, Catal. Today, 140, 142-148 (2009)

16. Z-T. Liu, J-L. Zhou, B-J. Zhang, J. Mol. Catal., 94, 255-261 (1994)

17. M. Luo, H. Hamdeh, B.H. Davis, Catal. Today 140, 127-134 (2009)

18. Y. Ohtsuka, T. Arai, S. Takasaki, N. Tsobouchi: Energ. Fuel., 17, 804-809 (2003)

19. J. Patzlaff, Y. Liu, C. Graffmann, J. Gaube, Appl. Catal., A 186, 109-119 (1999)

20. J. Wozniak, Energ. Policy, 15, 139-148 (2012)

21. H. Majchrzak, W. Krawczyk, Energetyka, 652 (2008)

22. X. Xiaoding, E.B.M Doesburg, J.J.F. Scholten, Catal. Today, 2, 125-170 (1987)

23. Fujimoto K., Shikada T, Appl. Catal, 31, 13-23 (1987)

24. G. R. Couch, Coal to liquids. (IEA Clean Coal Centre, $\mathrm{nr}$ CCC/132, 2008)

25. M. Stelmachowski M., Nowicki L.: Applied Energy 74, 85-93 (2003)

26. Skrzyńska E., Ogonowski J.: Nafta-Gaz, 8, 561-570 (2009)

27. Skrzyńska E., Ogonowski J.: Nafta-Gaz, 8, 601-608 (2009)

28. Skrzyńska E., Ogonowski J.: Nafta-Gaz, 1, 34-42 (2010)

29. W. Ptak, M. Sukiennik, Bulletin de l'Academie Polonaise des Sciences. Serie des sciences techniques, 17, 21-25 (1969)

30. W. Ptak, M. Sukiennik, R. Olesinski, R. Kaczmarczyk, Arch. Metall., 32, 355-362 (1987)

31. R. Kaczmarczyk, S. Gurgul, Arch. Metall. Mater., 59, 4, 1379-1383 (2014)

32. R. Kaczmarczyk, S. Gurgul S, Arch. Metall. Mater., 59, 1, 145-148 (2014)

33. O. Knacke, O. Kubaschewski, K. Hesselmann, Thermochemical Properties of Inorganic Substances (Berlin, Springer, 1991) 